\title{
Benefits of greenhouse gas mitigation on the supply, management, and use of water resources in the United States
}

\author{
K. Strzepek • J. Neumann • J. Smith • J. Martinich • \\ B. Boehlert • M. Hejazi • J. Henderson • C. Wobus • \\ R. Jones • K. Calvin • D. Johnson • E. Monier • \\ J. Strzepek • J.-H. Yoon
}

Received: 31 January 2013 / Accepted: 16 October 2014 / Published online: 29 November 2014

(C) The Author(s) 2014. This article is published with open access at Springerlink.com

\begin{abstract}
Climate change impacts on water resources in the United States are likely to be farreaching and substantial because the water is integral to climate, and the water sector spans many parts of the economy. This paper estimates impacts and damages from five water resource-related models addressing runoff, drought risk, economics of water supply/demand, water stress, and flooding damages. The models differ in the water system assessed, spatial scale, and unit of assessment, but together provide a quantitative and descriptive richness in characterizing water sector effects that no single model can capture. The results, driven by a consistent set of greenhouse gas (GHG) emission and climate scenarios, examine uncertainty
\end{abstract}

This article is part of a Special Issue on "A Multi-Model Framework to Achieve Consistent Evaluation of Climate Change Impacts in the United States" edited by Jeremy Martinich, John Reilly, Stephanie Waldhoff, Marcus Sarofim, and James McFarland.

Electronic supplementary material The online version of this article (doi:10.1007/s10584-014-1279-9) contains supplementary material, which is available to authorized users.

K. Strzepek $(\bowtie) \cdot$ E. Monier

Joint Program on the Science and Policy of Global Change, Massachusetts Institute of Technology,

Cambridge, MA, USA

e-mail: strzepek@mit.edu

J. Neumann · B. Boehlert · D. Johnson · J. Strzepek

Industrial Economics, Cambridge, MA, USA

J. Smith $\cdot$ J. Henderson $\cdot$ C. Wobus $\cdot$ R. Jones

Stratus Consulting, Boulder, CO, USA

J. Martinich

US Environmental Protection Agency, Climate Change Division, Washington, DC, USA

M. Hejazi $\cdot$ K. Calvin

Pacific Northwest National Laboratory, College Park, MD, USA

J.-H. Yoon

Pacific Northwest National Laboratory, Richland, WA, USA 
from emissions, climate sensitivity, and climate model selection. While calculating the net impact of climate change on the water sector as a whole may be impractical, broad conclusions can be drawn regarding patterns of change and benefits of GHG mitigation. Four key findings emerge: 1) GHG mitigation substantially reduces hydro-climatic impacts on the water sector; 2) GHG mitigation provides substantial national economic benefits in water resources related sectors; 3 ) the models show a strong signal of wetting for the Eastern US and a strong signal of drying in the Southwest; and 4) unmanaged hydrologic systems impacts show strong correlation with the change in magnitude and direction of precipitation and temperature from climate models, but managed water resource systems and regional economic systems show lower correlation with changes in climate variables due to non-linearities created by water infrastructure and the socio-economic changes in non-climate driven water demand.

\section{Introduction}

Climate change is projected to exacerbate current stresses on water resources, as these systems are highly sensitive to changes in climate. Some systems and regions are likely to be more affected than others, in part due to differences in the timing and magnitude of climate changes, interactions with local land-use, watershed characteristics, and human use and management. Quantifying and monetizing these potential future impacts, along with those that would occur in scenarios where greenhouse gas (GHG) emissions are mitigated, can provide useful information regarding the benefits of climate policy.

Analyses of climate change impacts on water resource management at the continental United States (CONUS) scale are difficult and rare, primarily due to data and modeling limitations, and because there are so many important issues to consider. Previous studies have focused on specific locations (Tanaka et al. 2006) or a set of medium-scale $\left(6,000-27,000 \mathrm{mi}^{2}\right)$ watersheds (Environmental Protection 2013), while others have focused on evaluating specific impacts, such as groundwater recharge (Taylor et al. 2013). Complicating factors for national-scale analysis in the United States (US) include the over 3,000 stream catchments covering 50 states and territories; 18 Koppen-Geiger climate zones (half of the global range); and 3 major water rights paradigms. Further, there is no national water supply policy. Water law is implemented at the state level, and interstate and international rivers are managed by compacts or treaties, respectively. Within the federal government, water issues are spread over 20 resource management, programmatic, and military agencies. As a result, national scale modeling requires a collection of technical capabilities that reflect the reality of water management, while remaining computationally tractable and reliable at the levels of temporal and spatial scale employed.

There does not exist a single national-scale model to comprehensively estimate the benefits (i.e., avoided impacts) to the water sector associated with GHG mitigation. However, a number of existing, peer-reviewed models have been developed and applied to estimate impacts on major parts of the water resource sector. The objective of this paper is to report a set of modeling exercises to estimate impacts for specific categories, including hydrologic variables (runoff), hydro-climatic metrics (drought indicators), water management indicators (water stress), damages from severe floods, and economic welfare (consumer and producer surplus). The analyses presented in this paper are part of a multi-sectoral, national-scale climate change impacts project, described in Waldhoff et al. (2014, this issue), that is designed to estimate the benefits of GHG mitigation in an integrated and consistent way (see Online Resource 1 for more details on the emission scenarios and climate projections). 
Four of the five analyses were conducted at the level of the 99 CONUS basins (the US Water Resources Council 1978 settled on 99 Assessment Sub-Regions, or ASRs, as the scale for national water policy analysis). The results from all five analyses are reported for 14 National Water Resource Regions (WRRs, a slight aggregation of the USGS 18 CONUS WRRs). Using the national scale results, this paper includes a quantitative synthesis to estimate impacts and GHG mitigation benefits across the water resource sector. The analysis on flooding damages, as reported in Wobus et al. (2013), is more closely dependent on assumptions about future infrastructure and extreme events than the other models reported here. Given the complexities inherent in projecting flood damages at a national scale and the limitation in the modeling of hydrologic extremes across spatial and temperoral scales and the assumption of no changes in infrastructure (e.g., Pielke and Downton 2000; Choi and Fisher 2003), flood damage results are reported here only as order-of-magnitude estimates for the WRRs. Improvements to the flood model are ongoing to better constrain changes in infrastructure, and to explicitly consider the tails of future precipitation distributions. Online Resource 2 provides additional details on the flooding analysis.

As noted below, the overall conclusion from the synthesis is that GHG mitigation matters and provides economic and other tangible benefits relative to a reference case. In the absence of a comprehensive, fully integrated model, a piecemeal approach to water sector modeling, as used in this paper, provides insights but also leaves important gaps in a full understanding of the benefits of mitigating GHGs. The sections below present a brief summary of the methodologies for each analysis along with key results. More detailed information on methodologies and other results can be found in the online supplemental material and referenced literature.

\section{The climate system}

Detailed descriptions of the GHG emission scenarios used in this analysis, along with a comparison to other emission scenarios (e.g., the Representative Concentration Pathways or RCPs) and global climate projections, are provided elsewhere in this special issue (Paltsev et al. 2013; Waldhoff et al. 2014). In short, three emission scenarios are used: a reference (REF) or 'business as usual', and two scenarios representing futures with policies that limit global GHG emissions such that total radiative forcing levels in 2100 are stabilized at $4.5 \mathrm{~W} /$ $\mathrm{m}^{2}$ (Policy 4.5) or $3.7 \mathrm{~W} / \mathrm{m}^{2}$ (Policy 3.7). The base framework used to project future climate, the NCAR Community Atmospheric Model linked with the MIT Integrated Global System Model (IGSM-CAM), is presented in Monier et al. (2013). Monier et al. (2014, this issue) also provides a summary of the simulations and details on the regional projections of climate change used in this study.

Strzepek and Schlosser (2010) and Boehlert et al. (2014) for CMIP3 and CMIP5 ensembles, respectively, report that each general circulation model (GCM) under GHG simulations exhibits a spatial pattern or signal of future changes relative to historic precipitation and temperature across regional, continental, and local scales that remains stable over time and GHG emission scenarios. This property of the GCM has been labeled the Emergent HydroClimatic Behavior (EHCB). Schlosser et al. (2012), have taken this property to develop a pattern-scaling approach that works with the MIT IGSM-2D atmospheric model to provide a set of hybrid gridded climate simulations. This pattern-scaling approach aims to address a key uncertainty in climate science; that is, the "structural uncertainty" from the EHCB coming from the physics and assumptions inherent to each GCM.

Since the IGSM-CAM only considers one GCM, the IGSM pattern scaling approach was used to develop a balanced set of regional patterns of climatic change for CONUS (see Monier 
et al. 2014, this issue, for methodological details). This approach preserves all the CIRA economic and emissions results, but replaces the CAM climate projections with projections based on the spatial patterns of alternative GCM-EHCBs. Two GCMs were chosen for the pattern-scaled results presented in this paper, each with very different patterns of change over CONUS: the Model for Interdisciplinary Research on Climate (MIROC3.2-medres) projects drying and a strong warming, and the Community Climate System Model (CCSM3.0) projects more moisture and less warming than MIROC. Monier et al. (2014, this issue) discusses how the IGSM-CAM simulations compare to the pattern-scaled MIROC and CCSM projections, as well as the limitations of both methods.

Additional details on these two climate projection techniques are provided in Online Resource 1, while the overview paper for the special issue (Waldhoff et al. 2014) further describes the rationale for selection of the emission scenario and climate projection methods. Unless otherwise indicated, the results presented below focus on the $3{ }^{\circ} \mathrm{C}$ climate sensitivity simulations, but in most cases, results for other climate sensitivities are included in the online supplemental material. The water resources impact assessment described in this paper utilizes both sets of climate change scenarios, the IGSM-CAM and the IGSM pattern-scaling, and each provide valuable insights. The impact assessments used bias-corrected IGSM projections with observed historical climate data as climate inputs.

\section{Assessing the impacts of climate changes on meteorological and agricultural droughts}

Drought can be defined as persistent extreme events that significantly affect the hydrological cycle by, for instance, decreasing rainfall, lowering stream-flow, or reducing soil moisture (Gonzalez and Valdes 2006). This analysis computes two drought indices for the baseline and two 21 st century time periods across the 99 ASRs. The approach involves three steps: (1) selecting appropriate drought indicators; (2) processing climate change scenario outputs to compute drought index values; and (3) estimating the number of drought months for each index under the current 30-year baseline and selected 30-year projection periods (i.e., centered on 2050 or 2100) to report the change in overall drought duration attributable to climate change. The drought index selection and processing methodology presented here closely follows the approach taken by Strzepek et al. (2010) in their characterization of US drought risk under a suite of 22 CMIP3 global climate models and three SRES emission scenarios.

This analysis includes indices that account for changes in both temperature and precipitation: Standardized Precipitation Index (SPI)-5 and SPI-12 (McKee et al. 1993; Warren et al. 2009), and four categories of Palmer Drought Severity Index (PDSI; Palmer 1965, 1968). SPI is a probabilistic index that measures drought based on divergences of precipitation in a given time period (e.g., one-month, one-year - the SPI-5 is a 5 month measure, SPI-12 is 12 months) and geographic area (e.g., state, watershed) from the historical median. PDSI, on the other hand, uses precipitation and temperature data to estimate the relative changes in a particular region's soil moisture. PDSI considers the meteorological conditions of both the current month and those of past months to account for the cumulative nature of drought.

While large parts of the CONUS are estimated to experience reductions in SPI-5 and SPI12 drought frequency under the REF scenario due to rising projected precipitation in the IGSM-CAM climate projections, the Southwestern US could experience pronounced increases in drought frequency, particularly under the $6{ }^{\circ} \mathrm{C}$ climate sensitivity. These regional increases in SPI-12 drought occurrence are dampened under the two GHG mitigation scenarios, as demonstrated by the large reductions in drought occurrence over the 30-year period when moving from the REF to the Policy 4.5 and 3.7 stabilization scenarios (Fig. 1a, left column). 
This pattern of GHG mitigation benefits falls between those demonstrated under the CCSM and MIROC GCM signatures of the IGSM pattern scaling runs (Fig. 1a, right column). The results clearly show that the climate realization effect is larger than the mitigation effect. Additionally we can have changes in the sign of the indicators between the eras due to differences in the relative changes in precipitation.

Findings for changes in PDSI drought frequency were similar to those of SPI, although the magnitude and pattern of changes differ somewhat because PDSI is cumulative and considers temperature in calculating the index value. As with SPI, the largest increases in drought frequency under the REF are in the Southwestern U.S., which is also where the largest benefits of mitigation occur (Fig. 1b, left column). Unlike the SPI droughts, however, the differences between reference and mitigation scenarios for the IGSM-CAM results show a much different spatial pattern than those of the pattern scaling GCM signatures, which tend to show the largest benefits through the Midwest rather than the Western U.S. (Fig. 1b, right column). The reader is referred to the online supplemental material (Online Resource 5) for the detailed results.

\section{Assessing impacts on CONUS runoff using a basin scale hydrologic model}

Change in streamflow is estimated by applying the CLIRUN lumped integral water balance model (Strzepek and Fant 2010). This model uses monthly projections of changes in temperature and precipitation to estimate changes in monthly streamflow. CLIRUN simulates the
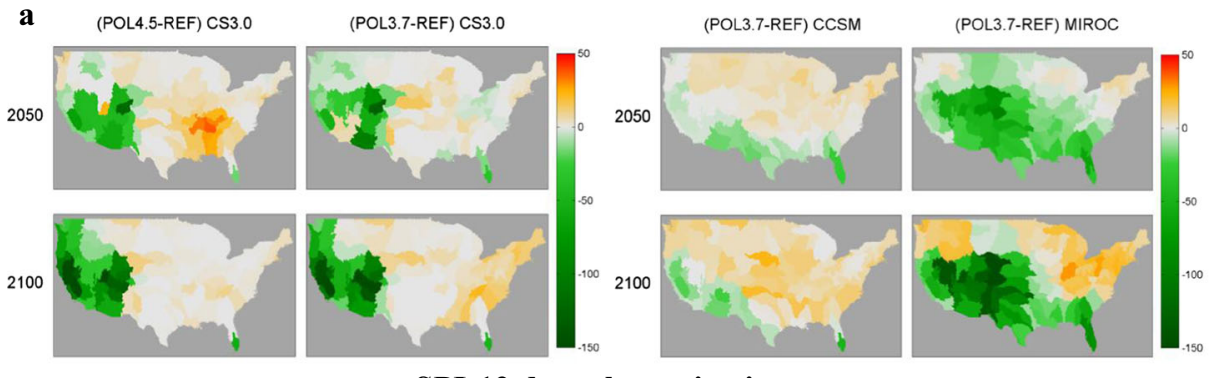

SPI-12 drought projections
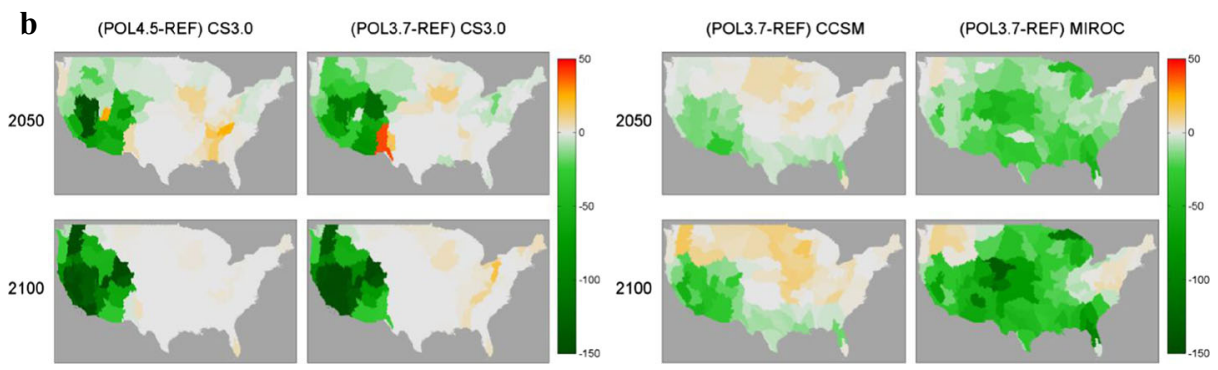

\section{PDSI drought projections}

Fig. 1 Drought Risk Results. a. Projected change in number of SPI-12 droughts months in a 30-year period due to mitigation (i.e., Policy 4.5 or Policy 3.7 minus REF), IGSM-CAM (left) and IGSM pattern-scaling (right) scenarios, 2050 and 2100 , for climate sensitivity (CS) $3.0^{\circ} \mathrm{C}$. Green colors reflect decreases in drought risk as a result of GHG mitigation; red colors reflect increases in drought risk as a result of GHG mitigation. b. Same as (a), but for projected change in number of PDSI extreme droughts months 
most important lumped hydrologic processes, including soil moisture storage, evapotranspiration, surface runoff, subsurface runoff, and base flow. CLIRUN was developed and designed to simulate the impacts of climate change on the water balance of medium- to large-scale catchments $\left(100-30,000 \mathrm{~km}^{2}\right)$ using a relatively restricted number of parameters. CLIRUN is specified and parameterized for the US at the 99-ASR level. Structural uncertainty due to model bias exists in all hydrologic analyses. Additionally in climate change analyses the use of GCM outputs and choice of bias correction technique add additional uncertainty. The reader is referred to the online supplemental material (Online Resource 1) for an example of these two issues.

Figure 2 shows the average change in runoff across all ASRs by time period computed by CLIRUN for IGSM-CAM scenarios. Ratios greater than one indicate an increase in runoff, while ratios less than one indicate a decrease. Under the REF scenario in 2100, there is a drying in the Southwest and a very large increase in runoff in the central CONUS. Under the Policy 3.7 and Policy 4.5 scenarios, we see smaller changes in runoff and drying in the Southwest, and much lower runoff increases in the central CONUS.

\section{Assessing water resources welfare impacts using an basin scale hydro-economic supply demand model}

A national-scale optimization model (Henderson et al. 2013) was used to generate estimates of the economic impacts associated with changes in both supply and demand of water (see Online Resource 3 for full methodological details). The model is a spatial-equilibrium simulation of
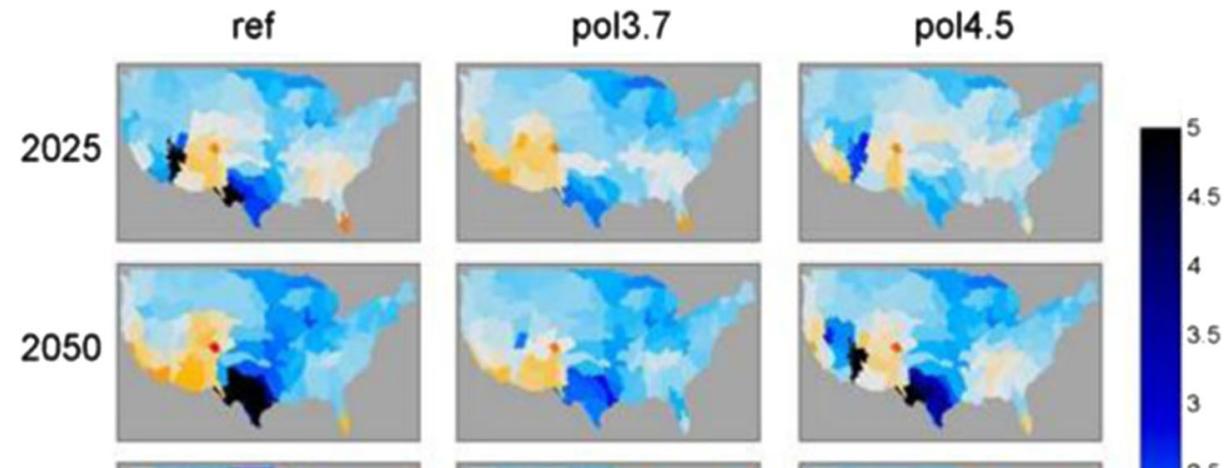

2050
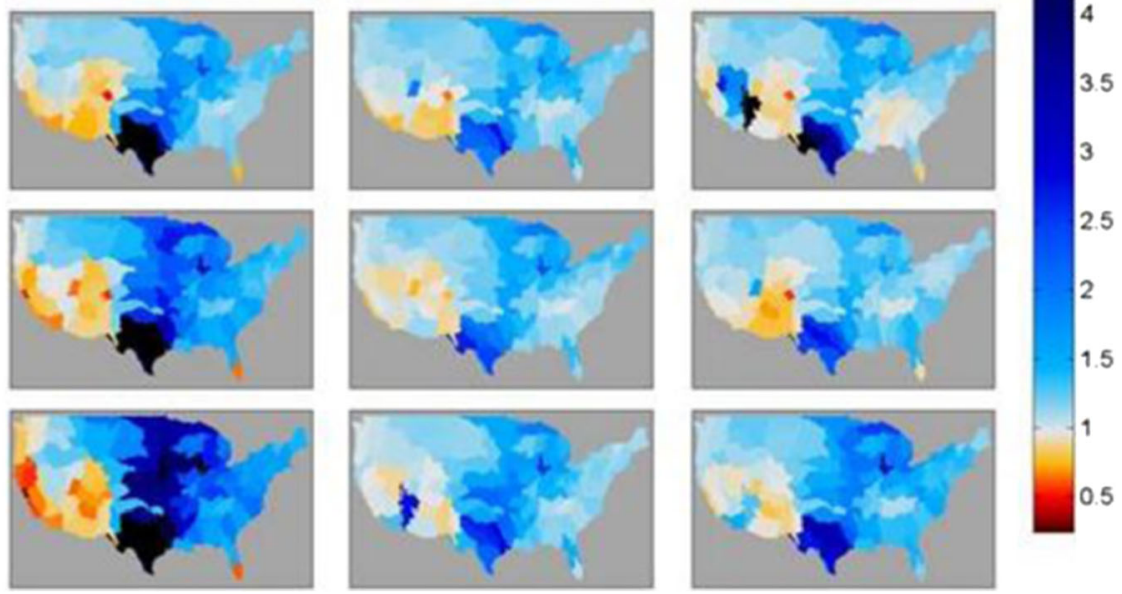

Fig. 2 Ratio of Mean Annual Runoff in a 30-year baseline (1980-2009) to 30-year period under the Ref, Policy 3.7, and Policy 4.5 scenarios for the IGSM-CAM projections. Blue colors indicate increases in runoff relative to the historic baseline, red colors indicate decreases in runoff relative to the historic baseline 
the water balance for each water use region using a representative reservoir. The hydrologiceconomic modeling approach has been applied in several studies, especially to evaluate water scarcity and the effect of water transfers (e.g., Booker 1995; Vaux and Howitt 1984). A separate model is built for each of the 99 ASRs with results aggregated to the WRRs. Demand in each ASR incorporates the US population projections described in Paltsev et al. (2013, this issue). Other model inputs include change in runoff from the analysis described above and inputs to irrigation demand and reservoir evapotranspiration, which vary by climate scenario. Each regional model maximizes the benefits from water use subject to a wide range of constraints, such as storage and conveyance capacities and sustainable groundwater recharge limits. Other region-specific constraints represent legal and institutional frameworks governing water allocation, and consideration of the water needs of the physical environment (sometimes referred to as "environmental flow requirements").

The supply and demand model results are sensitive to projected change in runoff and evaporation. These factors are projected to vary greatly by region and across climate change scenarios, and as a result, national level economic impact estimates differ across the scenarios. In Fig. 3, the IGSM-CAM REF scenario indicates a welfare increase of $\$ 0.5$ billion per year in 2050 - under the Policy 3.7 scenario, the welfare increase jumps to $\$ 3.8$ billion. However by 2100 , the model estimates decreases in welfare of $\$ 6.5$ billion per year under the REF scenario, while the Policy 3.7 results in an increase in welfare of $\$ 2.9$ billion. Thus, the total benefit of the GHG mitigation scenario is estimated to be $\$ 3.3$ billion per year in 2050 and $\$ 9.4$ billion per year by 2100 . Figure 3 a illustrates the spatial variation across the CONUS.
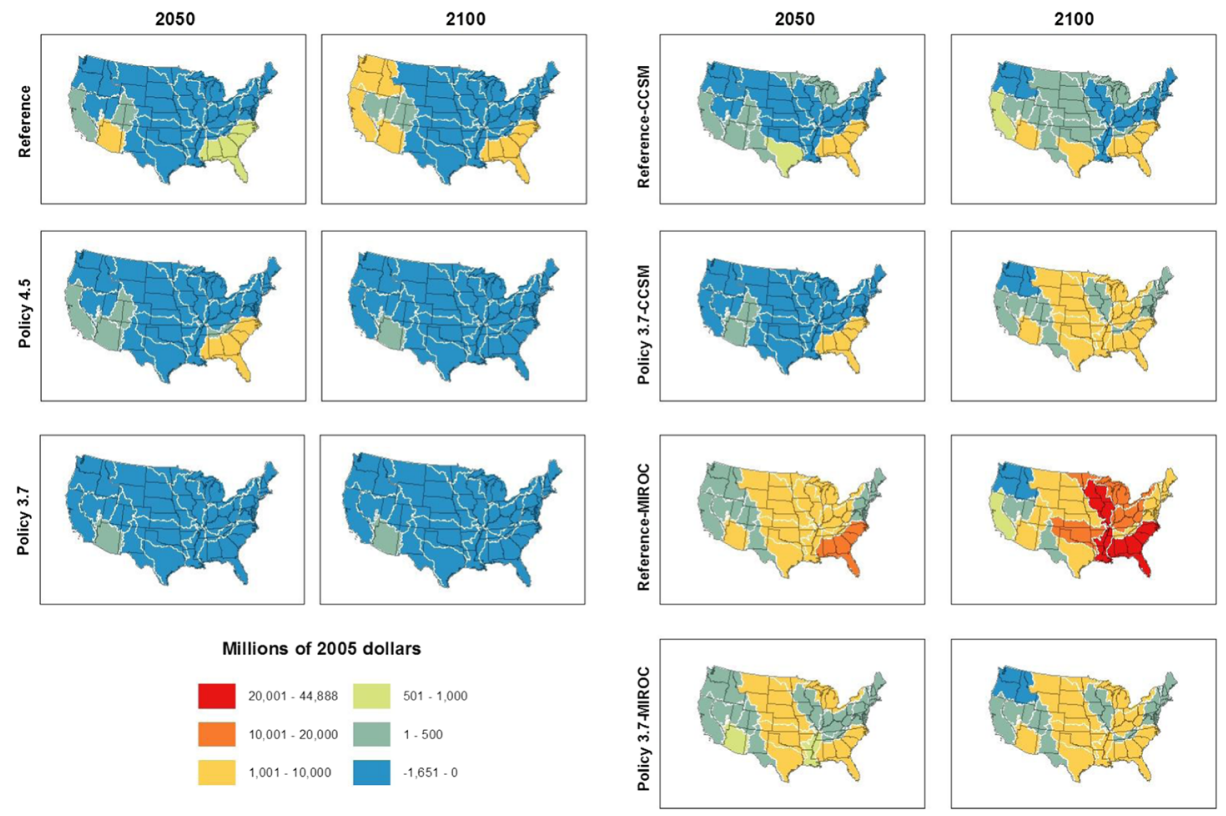

a) IGSM-CAM

b) IGSM-Pattern Scaling

Fig. 3 Changes in economic damages (millions of 2005\$) relative to the historic baseline for the REF and GHG mitigation (Policy 3.7 and Policy 4.5) scenarios. Red areas indicate increase in damages, blue areas indicate decreases in damages (i.e., increases in welfare). Panel a: IGSM-CAM model results for 2050 and 2100, Panel b: CCSM and MIROC model results for 2050 and 2100 
The climate projection sensitivity analyses using IGSM pattern scaling in Fig. 3b yield similar results but with very different magnitudes of impacts. Under the REF CCSM scenario in 2100 , the model estimates $\$ 15.0$ billion in decreased welfare, but the welfare loss is reduced by $\$ 14.5$ billion per year under the Policy 3.7 scenario in 2100 . Under the hotter and drier MIROC pattern, the REF MIROC scenario in 2100 yields a welfare loss of over $\$ 100$ billion per year $^{1}$, while the Policy 3.7 MIROC scenario reduces the annual welfare loss to $\$ 16$ billion. Figure $3 \mathrm{~b}$ illustrates the spatial variation. Additional modeling results for the IGSM-CAM and IGSM pattern scaled projections are provided in Tables 1, 2, and 3 of Online Resource 3.

Environmental flow penalty (representing harm to aquatic ecosystems) is the largest category accounting for over $80 \%$ of national damages in 2100 under all three climate model results with details in Tables 1, 2, and 3 of Online Resource 3. A large majority of the environmental flow penalty under all scenarios is estimated for regions with projected decreases in runoff, especially during summer and early fall months, in western WRRs (Lower Colorado, Great Basin, Pacific Northwest and California) and the South Atlantic Gulf WRR.

As described above, GHG mitigation enhances welfare compared to the REF. However, the economic supply and demand model does not estimate capital expenses for new infrastructure or welfare losses due to flooding, a potentially important factor in wet climate projections, such as those used here from the IGSM-CAM - meaning the benefits of GHG mitigation could be even larger. The flooding damages model (Wobus et al. 2013) applied as part of this project (see Online Resource 2) reports that the REF scenario results in statistically significant increases in flooding losses for 10 of the WRRs in the US in 2100. The Policy 3.7 mitigation scenario reduces the number of WRRs with flooding losses to six, with an overall increase in welfare on the order of $\$ 2.5$ billion dollars per year by 2100 relative to the Reference results.

\section{Assessing impact on water stress using the water module within an integrated assessment model (GCAM)}

The Global Change Assessment Model (GCAM) is a dynamic-recursive model combining representations of the global economy, the energy system, agriculture and land use, water, and climate (Edmonds and Reilly 1985; Kim et al. 2006; Clarke et al. 2007). Exogenous inputs include (among other variables) present and future population, labor productivity, energy and agricultural technology characteristics, and resource availabilities. The model is calibrated to historical energy, agricultural, land, and climate data and market-clearing prices for all energy, agriculture, and land markets such that supplies and demands of all modeled markets are in equilibrium. In GCAM, the water system includes both supply and demand modules. The water system model result that was used in this analysis was the water stress index (WSI; Raskin et al. 1997 and Wada et al. 2011).

GCAM uses a gridded monthly water balance model with a resolution of $0.5 \times 0.5$ degrees. Water routing capabilities and reservoir operation rules are not included. The water supply module is first evaluated against observational data and other models, and then simulated into

\footnotetext{
${ }^{1}$ The model is a partial equilibrium model and is designed to estimate marginal changes from a reference case. The REF-MIROC scenario is extremely dry and most of the damages come from environmental flow damages, but no adaptation options are incorporated. A more comprehensive analysis would incorporate non-marginal infrastructure and economic responses to such large impacts (with their own economic implications), with the likely result that very large damages such as this could be reduced significantly. Regardless of the adaptation modeling conducted, the MIROC scenarios do provide an important indicator of the potential risks of significant economic impacts of climate change for this sector.
} 
the future to provide estimates of total water supply up to the end of the 21 st century (see Hejazi et al. 2014a and Online Resource 4).

Six water demand components are endogenously modeled in GCAM: agriculture (irrigation and livestock); primary energy production; secondary energy production; manufacturing; mining; and the municipal sector (Hejazi et al. 2014b). The energy, industrial, and municipal sectors are represented in 14 geopolitical regions, with the agricultural sector further disaggregated into up to 18 agro-ecological zones within each region. In-stream water demands for uses such as ecosystem services, navigation, and recreation are not addressed in the model. However, hydropower water use is included within the electric power sector, as documented in Davies et al. (2013).

Under the REF scenario, total irrigation water demands double in magnitude (from $163 \mathrm{~km}^{3} / \mathrm{yr}$ in 2005 to $330 \mathrm{~km}^{3} / \mathrm{yr}$ in 2095) primarily due to increases in biomass and crop production attributed to higher food and energy demands; a similar doubling is also projected for domestic water use (from $69 \mathrm{~km}^{3} / \mathrm{yr}$ in 2005 to $103 \mathrm{~km}^{3} / \mathrm{yr}$ in 2095). On the other hand, energy water use and primarily thermoelectric cooling water demand diminishes by approximately $70 \%$ due to a shifting away from once-through cooling technology to more efficient cooling technologies (from $231 \mathrm{~km}^{3} / \mathrm{yr}$ in 2005 to $70 \mathrm{~km}^{3} / \mathrm{yr}$ in 2095). These shifts in US water demands become more pronounced under futures that include GHG mitigation. Water demands for irrigation increase by $13 \%$ to $373 \mathrm{~km}^{3} / \mathrm{yr}$ in 2095 to increase biomass production and water demand for energy use falls by $10 \%$ to $63 \mathrm{~km}^{3} / \mathrm{yr}$ because of reduced demand.

Figure 4 shows the change in WSI in 2095 under each of the eight simulated scenarios. Under mitigation policy scenarios, the Rio Grande experiences the greatest increase in water stress by the end of the century. Under the IGSM pattern-scaled scenarios, the CCSM and MIROC results generally show less runoff and exacerbated water stress conditions in most basins, especially in the Great Plain region. Additional results are provided in Online Resource 4.

\section{Synthesis}

This section provides a national and regional synthesis of results across the emission scenarios, climate models, and impact modeling approaches analyzed in this paper. The detailed summary results by the WRRs of the CONUS are provided in Table 1 of Online Resource 5. Four findings emerge from the analysis of the results:

Finding 1 GHG mitigation reduces the hydro-climatic impacts of the REF. In regions where the models project wetting under the REF scenario (relative to current climate), GHG mitigation reduces wetting; where the models project drying, mitigation reduces drying.

Figure 5 provides a CONUS-wide summary of the modeling results for 2100 , assuming a climate sensitivity of $3{ }^{\circ} \mathrm{C}$ for the REF and policy scenarios for the IGSM-CAM and pattern scaled (CCSM and MIROC) outputs. The four panels provide the runoff weighted mean of the values over the WRRs for runoff (a), drought (b), economic welfare (c), and water stress (d). For the economic supply and demand impacts, we report the simple sum over the WRRs.

The REF scenario results in 2100 show a CONUS-wide average increase of mean annual runoff of $100 \%$. However, this is not uniform across the WRRs, and as seen in Figure 6 and Table 1 of Online Resource 5 is the result of drying in the Southwest, wetting in the Northeastern and Southeastern US, and substantial wetting in the Central CONUS WRRs. 


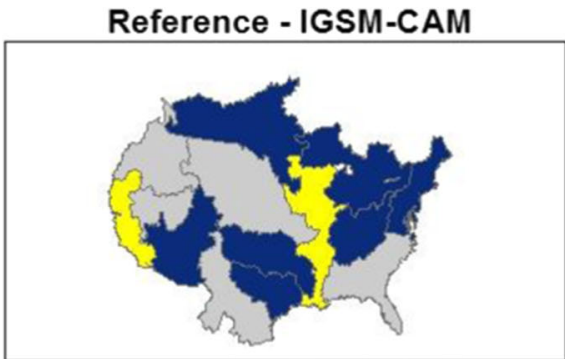

\section{Reference CS6 $^{\circ}$ - IGSM-CAM}

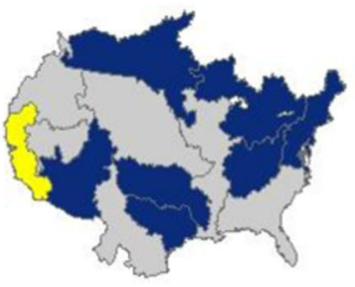

\section{Reference - CCSM}

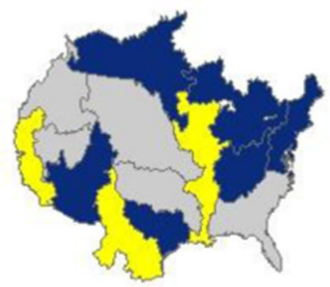

Reference - MIROC

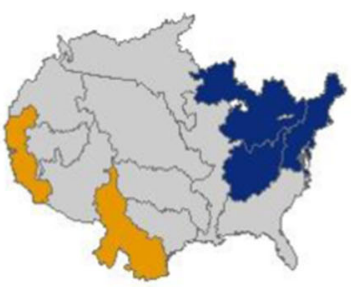

$-0.2-0.0$

$0.0-0.2$

$0.2-0.4$

$0.4-0.8$

$0.8-1.2$
Policy 4.5 - IGSM-CAM

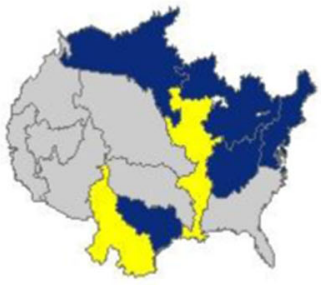

Policy 3.7 - IGSM-CAM

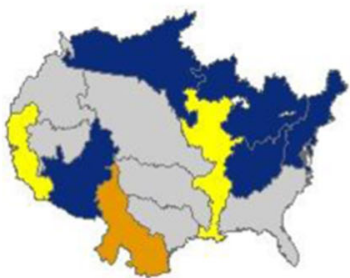

Policy 3.7 - CCSM

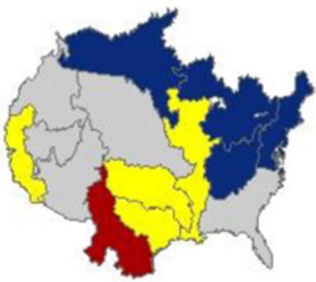

Policy 3.7 - MIROC

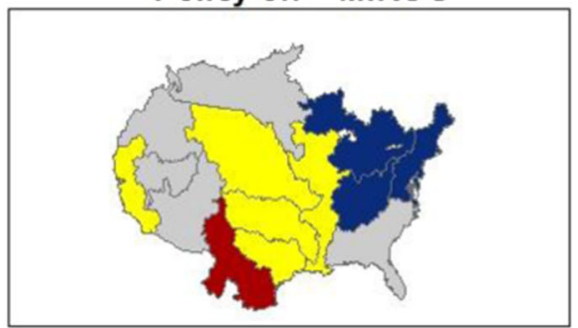

Note: Results are for a climate sensitivity of three degrees Celsius unless otherwise noted.

Fig. 4 Change in water stress index between years 2005 and 2095. A positive (negative) value implies a water stress increase (decrease) by the end of the century

Figure 5a shows that mitigation policies do lessen the substantial increase in CONUS-wide runoff for the IGSM-CAM scenarios. The pattern scaling results show that GHG mitigation reduces the decreases of runoff with the dry (MIROC) model and reduces the increases of runoff with the wet (CCSM) model. Similarly, the number of PDSI droughts follows an 

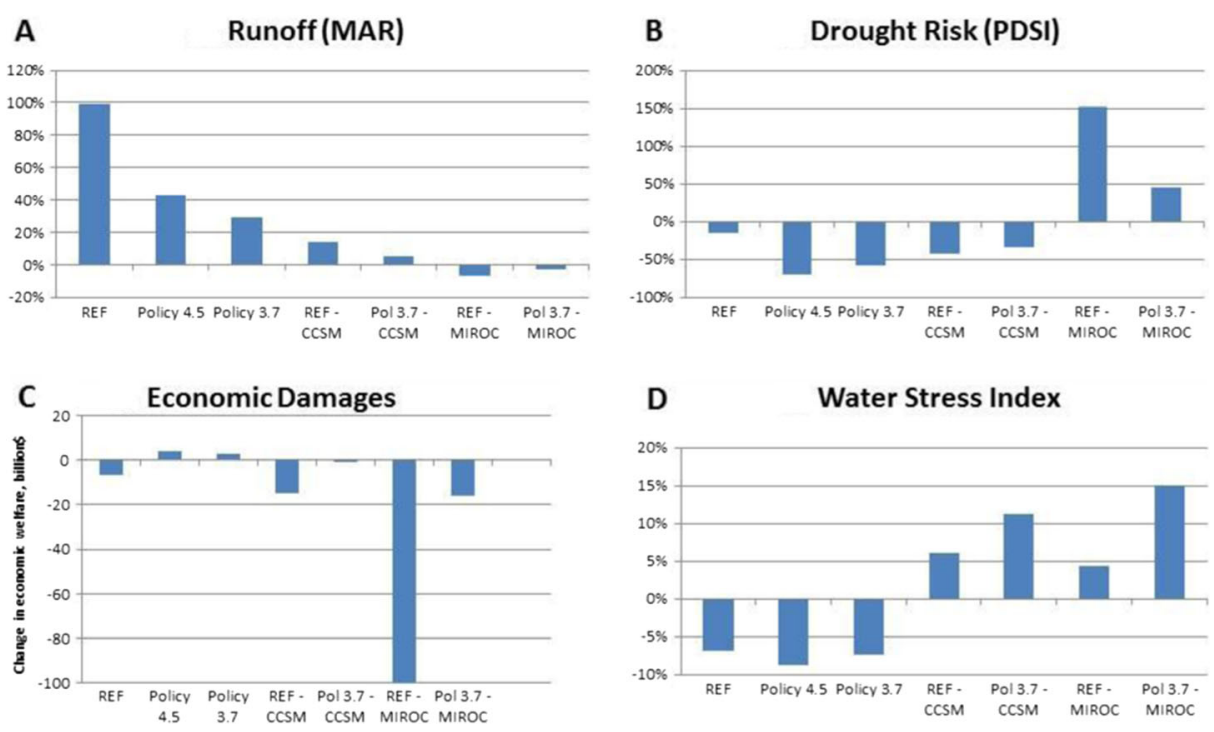

Fig. 5 CONUS wide results for IGSM-CAM REF, Policy 4.5, and Policy 3.7 scenarios, and REF and Policy 3.7 for IGSM-pattern-scaled (CCSM and MIROC) scenarios. MAR is Mean Annual Runoff, PDSI is Palmer Drought Severity Index, see text for further explanations

inverse pattern to that for runoff, with decreasing droughts associated with more runoff and increasing droughts with less runoff, which suggests the same "extreme-reducing" benefit from GHG mitigation.

Finding 2 The economic model projects substantial benefits of GHG mitigation for national economic welfare in water related sectors. However, the magnitude of the results must be taken with caution. This model assumes static water infrastructure, which can affect the magnitude of total impacts.

The economic analysis of supply and demand, reported as changes in economic welfare (in 2005\$) for each WRR, is presented in Fig. 5c) for CONUS and in Fig. 6 by WRR. These results show substantial welfare decreases for the South Gulf WRR due to environmental flow impacts, and the Lower Colorado, California, and Pacific Northwest WRRs due to decreases in hydropower generation under the IGSM-CAM (upper panel of Fig. 6) and MIROC REF (lower panel of Fig. 6) scenarios resulting from regional drying. The magnitude of the negative impacts of these four WRRs dominates over the minor positive and negative impacts in the other 14 WRRs where there are increases in runoff. Since the hydro-economic model has a static water infrastructure, it is not able to take advantage of the increased flow, so some potential positive benefits of an expanded infrastructure portfolio are not realized, but it does capture the negative impacts of reduced flows.

Figure $5 \mathrm{~d}$ shows the range of changes in the WSI using the GCAM model across the WRRs. Care must be taken in interpreting these results as these are changes in WSI measured from 2000 conditions. The 2100 water demands include the increases in non-agricultural water demands from socio-economic growth that will occur with or without climate change. Further, the water demands for irrigation of biofuels is substantially modified by climate policy - this 

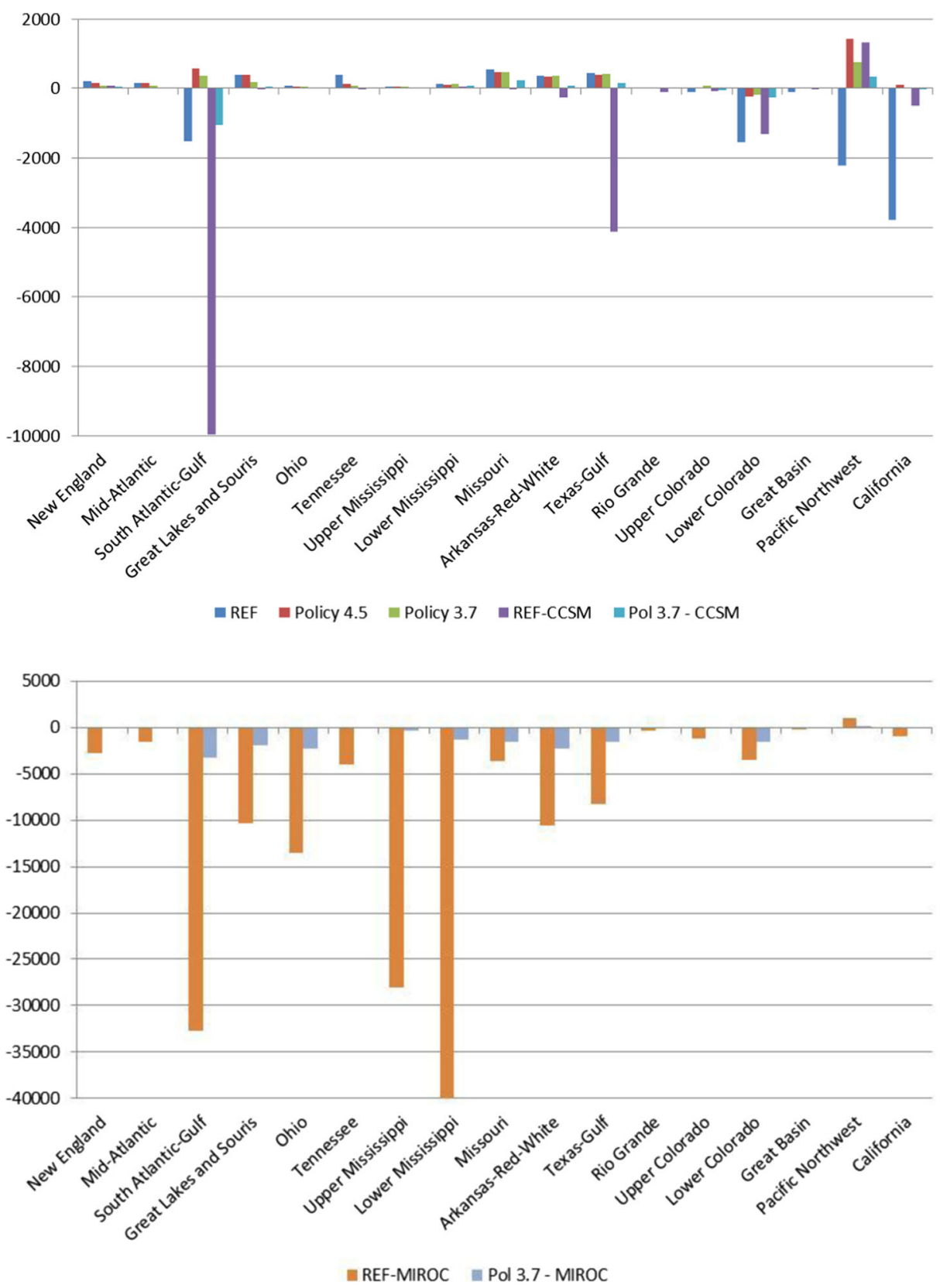

Fig. 6 Supply/demand balance annual economic welfare estimates in 2100 by WRR for REF and GHG mitigation scenarios (million 2005\$). The IGSM-CAM and CCSM results in the upper panel, MIROC results in the lower panel; note the significant difference in the vertical scale of the lower versus upper panels

result is a potentially interesting finding of an integrated economic approach. The results in their current form suggest that climate policy-driven water demands will show changes in 2100 
primarily from increases in irrigation demand for agricultural biofuels, and coupled with drying in the Southwest will increase water stress in those WRRs and for many other WRRs. ${ }^{2}$

Finding 3 The analyses herein show a very strong signal of wetting for the Eastern US, particularly the northeastern WRRs, and a strong signal of drying of the southwestern WRRs. Some substantial increases in water stress at a regional scale is suggested.

As noted above for all categories of effects, the national results for runoff, drought, economic welfare, and WSI in Fig. 5 reflect pronounced regional patterns. These are shown for runoff in Figure 1 of Online Resource 5, and economic welfare in Fig. 6. In addition, an informal analysis of the spatial consistency in results across the analyses in this paper can be inferred from inspection of Figs. 1 through 4 . Spatially we see that climate change provides strongly positive increases in welfare in the Northeastern US WRRs, and strong decreases in welfare in the Southwestern US WRRs. Results for the Central US WRRs show a more mixed result, in part because the projection of much higher runoff in the IGSM-CAM and CCSM pattern-scaled scenarios both increase welfare in some sectors (e.g., droughts) and lead to damages in other sectors (e.g., floods).

Finding 4 The unmanaged hydrologic systems impacts tend to show strong correlation with the change in magnitude and direction of precipitation and temperature from climate models, but managed water resource systems and regional economic systems impacts tend to show low correlation with changes in climate variables due to non-linear effects of water infrastructure and the socio-economic changes in non-climate driven water demand. This suggests that the analytical and policy questions being analyzed in a particular assessment, and the tools or models employed, have an impact on the ultimate results. Therefore, multi-metric analyses are needed to address the range of impacts faced in the water sector.

It was not possible to develop a meaningful multi-attribute indicator that could integrate the four analyses into a single value, as each analysis is addressing a very specific impact. The synthesis of results presented here, however, raises the question of whether a single metric can be developed to reflect the full range of impacts to the climate sensitive water resources sector. An argument can be made that, to inform GHG mitigation policies that imply the expenditure of economic resources, an economic welfare measure of the benefits of these policies would be most appropriate. Yet, the importance of induced infrastructure investments (such as modification of hydropower and flood management reservoirs and associated capital), and the effects of GHG mitigation itself on water demand (e.g., the potentially important effect of increased biofuels demand), is beyond the scope of the economic welfare model. In addition, some categories of impacts, such as the availability of cooling water for thermoelectric plants, are omitted from the currently available methodologies. Research continues to improve the economic welfare estimates presented here, but in the interim it appears clear that each of the five characterizations of water resource impacts presented in this paper contributes a unique component of understanding of the full impact of climate change on water resources. A logical extension of this argument is that multiple metrics, and a nuanced interpretation of

\footnotetext{
${ }^{2}$ Additional care must be taken when interpreting relative changes in water stress as WRRs with low estimates of water stress (e.g. WSI $=0.005$ ) could have an increase in water stress by a factor of 20 (to WSI $=0.1$ ) but remain with low water stress in absolute terms, resulting in little to no economic or ecological impacts.
} 
their joint implications, remains necessary to adequately characterize the effects of GHG mitigation on this complex sector. ${ }^{3}$ A clear message is that, because the water sector affects a wide range of economic activity, water sector impacts should be addressed with an integrated assessment framework that includes socio-economic growth projections which are linked to climate and energy policies that drive water demand.

The key areas for future research to expand the comprehensiveness of the impact assessment and provide a higher scale of sectoral and spatial results include the following: 1) modeling hydropower and supply demand balances at a finer spatial resolution; 2) hydroeconomic modeling of flooding at the local scale, and inclusion of flooding in basin level hydro-economic modeling; 3) water quality modeling; 4) assessment of thermal electric cooling water requirements and river temperature modeling at CONUS scale; 5) expansion of the breadth of climate projections analyzed, including a broader list of atmospheric models that can produce three-dimensional climate projections that reflect the real possibilities of both wet and dry outcomes for the US, to ensure that both mitigation and adaptation policies are robust to the full range of climate projection uncertainties.

Open Access This article is distributed under the terms of the Creative Commons Attribution License which permits any use, distribution, and reproduction in any medium, provided the original author(s) and the source are credited.

\section{References}

Boehlert, B, Strzepek, K. and Solomon, S. (2014) "Uncertainty in GCM projections for global and US water resources" MIT Joint Program Report Series, In Preparation

Booker JF (1995) Hydrologic and economic impacts of drought under alternative policy responses. Water Resour Bull 31:889-906

Choi O, Fisher A (2003) The impacts of socioeconomic development and climate change on severe weather catastrophe losses: Mid-Atlantic region and the US. Clim Chang 58:149-170

Clarke L, Lurz J, Wise M et al (2007) Model documentation for the MiniCAM climate change science program stabilization scenarios. Pacific Northwest National Laboratory, Richland

Council on Environmental Quality (2013) Principles and Requirements for Federal Investments in Water Resources. Washington, DC. Available at: http://www.whitehouse.gov/administration/eop/ceq/initiatives/PandG

Davies E, Kyle P, Edmonds JA (2013) An integrated assessment of global and regional water demands for electricity generation to 2095. Adv Water Resour 52:296-313. doi:10.1016/j.advwatres.2012.11.020

Edmonds J, Reilly J (1985) Global energy: assessing the future. Oxford University Press, New York

Environmental Protection Agency (2013) Watershed modeling to assess the sensitivity of streamflow, nutrient, and sediment loads to potential climate change and urban development in 20 U.S. watersheds. National Center for Environmental Assessment, EPA/600/R-12/058A

Gonzalez J, Valdes J (2006) New drought frequency index: definition and comparative performance analysis. Water Resour Res 42:W11421

Hejazi M, Edmonds J, Clarke L et al (2014a) Integrated assessment of global water scarcity over the 21st century under multiple climate change mitigation policies. Hydrol Earth Syst Sci 18:2859-2883. doi:10.5194/hess18-2859-2014

Hejazi M, Edmonds J, Clarke L et al (2014b) Long-term global water use projections using six socioeconomic scenarios in an integrated assessment modeling framework. Technol Forecast Soc Chang 81:205-226. doi: 10.1016/j.techfore.2013.05.006

\footnotetext{
${ }^{3}$ It is worth noting that the use of multiple metrics, principles, and objectives has been the cornerstone of US Federal water resources planning and assessment for at least 30 years. See, for example, Major (1977) and Council on Environmental Quality (2013). The point we make here is that, even for the narrow purposes of evaluating the impact of climate change on water resources, multi-metric assessment remains necessary.
} 
Henderson J, C Rodgers, R Jones, J Smith, K Strzepek and J Martinich (2013) "Economic impacts of climate change on water resources in the coterminous United States." Mitigation and Adaptation Strategies for Global Change): $1-23$

Kim S, Edmonds J, Lurz J, Smith S, Wise M (2006) The object-oriented energy climate technology systems (ObjECTS) framework and hybrid modeling of transportation in the MiniCAM long-term, global integrated assessment model. Energy J 27:63-92

Major DC (1977) Multiobjective water resource planning. American Geophysical Union, Washington, Water Resources Monograph 4

McKee TN, Doesken N, Kleist J (1993) The relationship of drought frequency and duration to time scales. Proc. 9th conf. On applied climatology. American Meteorological Society, Boston, pp 179-84

Monier E, Scott JR, Sokolov AP, Forest CE, Schlosser CA (2013) An integrated assessment modeling framework for uncertainty studies in global and regional climate change: the MIT IGSM-CAM (version 1.0). Geosci Model Dev 6:2063-2085. doi:10.5194/gmd-6-2063-2013

Monier E, Gao X, Scott J, Sokolov A, Schlosser A (2014) A framework for modeling uncertainty in regional climate change. Clim Chang. doi:10.1007/s10584-014-1112-5

Palmer W (1965) Meteorological drought. Research paper no. 45. US Department of Commerce Weather Bureau, Washington

Palmer W (1968) Keeping track of crop moisture conditions, nationwide: the new crop moisture index. Weatherwise 21:156

Paltsev S, Monier E, Scott J, Sokolov A, Reilly J (2013) Integrated economic and climate projections for impact assessment. Clim Chang. doi:10.1007/s10584-013-0892-3

Pielke R Jr, Downton MW (2000) Precipitation and damaging floods: trends in the United States, 1932-97. J Clim 13:3625-3637

Raskin P, Gleick P, Kirshen P, Pontius G, Strzepek K (1997) Water futures: assessment of long-range patterns and prospects. Stockholm Environment Institute, Stockholm

Schlosser CA, Gao X, Strzepek K, Sokolov A, Forest CE, Awadalla S, Farmer W (2012) Quantifying the likelihood of regional climate change: a hybridized approach. J Clim 26(10):3394-3414. doi:10.1175/JCLID-11-00730.1

Strzepek K, Fant C (2010) Water and climate: modeling the impact of climate change on hydrology and water availability (Washington DC: The World Bank) http:/documents.worldbank.org/curated/en/2010/09/12815320/ modeling-impact-climate-change-global-hydrology-water-availability. Accessed December 302013

Strzepek K, Schlosser CA (2010) Climate change scenarios and climate data, world bank economics of adaptation to climate change, discussion paper number 9 . The World Bank, Washington

Strzepek K, Yohe G, Neumann J, Boehlert B (2010) Characterizing changes in drought risk for the United States from climate change. Environ Res Lett. doi:10.1088/1748-9326/5/4/044012

Tanaka S, Zhu T, Lund JR, Howitt RE, Jenkins MW, Pulido MA, Tauber M, Ritzema RS, Ferreira IC (2006) Climate warming and water management adaptation for California. Clim Chang. doi:10.1007/s10584-0069079-5

Taylor RG, Scanlon B, Döll P, Rodell M, van Beek R, Wada Y, Longuevergne L, Leblanc M, Famiglietti JS, Edmunds M, Konikow L, Green TR, Chen J, Taniguchi M, Bierkens MFP, MacDonald A, Fan Y, Maxwell RM, Yechieli Y, Gurdak JJ, Allen DM, Shamsudduha M, Hiscock K, Yeh PJ-F, Holman I, Treidel H (2013) Ground water and climate change. Nat Clim Chang 3(4):322-329. doi:10.1038/nclimate1744

US Water Resources Council (1978) The nation's water resources 1975-2000. U.S. Government Printing Office, Washington

Vaux HJ, Howitt RE (1984) Managing water scarcity: an evaluation of interregional transfers. Water Resour Res 20:785-792

Wada Y, van Beek L, Viviroli D, Dürr H, Weingartner R, Bierkens M (2011) Global monthly water stress: water demand and severity of water stress. Water Resour Res 47(7):W07518

Waldhoff S, Martinich J, Sarofim M, DeAngelo B, McFarland J, Jantarasami L, Shouse K, Crimmins A, Ohrel S, Li J (2014) Overview of the Special Issue: A multi-model framework to achieve consistent evaluation of climate change impacts in the United States. Climatic Change. doi:10.1007/s10584-014-1206-0

Warren R, Yu R, Osborn T, de la Nava Santos S (2009) Future European drought regimes under mitigated and un-mitigated climate change. IOP Conf Ser Earth Environ Sci 6:292012

Wobus C, Lawson M, Jones R, Smith J, Martinich J (2013) Estimating monetary damages from flooding in the United States under a changing climate. J Flood Risk Manage. doi:10.1111/jfr3.12043 